IZA DP No. 6390

Gender Differences in Education

Tuomas Pekkarinen

February 2012 


\title{
Gender Differences in Education
}

\author{
Tuomas Pekkarinen \\ Aalto University School of Economics, \\ IFAU and IZA
}

\section{Discussion Paper No. 6390 \\ February 2012}

\author{
IZA \\ P.O. Box 7240 \\ 53072 Bonn \\ Germany \\ Phone: +49-228-3894-0 \\ Fax: +49-228-3894-180 \\ E-mail: iza@iza.org
}

\begin{abstract}
Any opinions expressed here are those of the author(s) and not those of IZA. Research published in this series may include views on policy, but the institute itself takes no institutional policy positions.

The Institute for the Study of Labor (IZA) in Bonn is a local and virtual international research center and a place of communication between science, politics and business. IZA is an independent nonprofit organization supported by Deutsche Post Foundation. The center is associated with the University of Bonn and offers a stimulating research environment through its international network, workshops and conferences, data service, project support, research visits and doctoral program. IZA engages in (i) original and internationally competitive research in all fields of labor economics, (ii) development of policy concepts, and (iii) dissemination of research results and concepts to the interested public.
\end{abstract}

IZA Discussion Papers often represent preliminary work and are circulated to encourage discussion. Citation of such a paper should account for its provisional character. A revised version may be available directly from the author. 
IZA Discussion Paper No. 6390

February 2012

\section{ABSTRACT}

\section{Gender Differences in Education *}

This paper surveys the trends in gender gaps in education, their causes and potential policy implications. I show that female educational attainment has surpassed, or is about to surpass, male educational attainment in most industrialized countries. These gaps reflect male overrepresentation among secondary school drop-outs and female overrepresentation among tertiary education students and graduates. Existing evidence suggests that this pattern is a result of a combination of increasing returns to education and lower female effort costs of education. Widening gender gap in education combined with recent wage and employment polarization will likely lead to widening inequalities and is linked to declining male labor force participation. The paper discusses evidence on educational policies that both widen and reduce gender gaps in educational outcomes.

JEL Classification: $\quad$ I20, J160, J240

Keywords: education, gender differences, test scores

Corresponding author:

Tuomas Pekkarinen

Aalto University

School of Economics

Department of Economics

Box 21210

00076 Aalto

Finland

E-mail: tuomas.pekkarinen@aalto.fi

\footnotetext{
* Paper prepared for the Nordic Economic Policy Review Conference in Oslo, 24 Oct. 2011. The author gratefully acknowledges the financial support by the Academy of Finland.
} 
One of the most striking trends in education in the past two or three decades has been the rapid increase in female educational attainment. From the cohorts born in the 1950's onwards women quickly caught up with men in educational investment. Furthermore, it is clear that the growth in the educational attainment of women has not stalled at gender parity. At the moment, female educational attainment clearly dominates male educational attainment in a majority of industrialized countries. This is true for several measures of attainment. Women are in clear majority among secondary school graduates, among students enrolled in tertiary education, and among tertiary graduates. Furthermore, judging from recent trends it seems likely that gender gap in educational attainment will keep on widening in favor of women in the future.

These trends imply a dramatic change in the composition of the skill supply in industrialized economies. Whereas in the post WWII industrialized world men were substantially overrepresented among the highly skilled workers, this will not be true in the coming decades. And this change happens at a time when educational investments are becoming more and more important for labor market outcomes. In particular, the recent trend of employment polarization will likely lead to more pronounced differences between the labor market fortunes of high- and low-skilled workers. Gender differences in educational attainment imply that these highly rewarded high-skill workers will be predominantly female and increasingly disadvantaged low-skill workers will be predominantly male. Gender gap in educational attainment can therefore have far reaching labor market implications.

The aim of this article is to provide an overview of the trends in gender differences in educational attainment and to examine their potential causes as well as implications for labor market outcomes. When it comes to documenting the trends, the emphasis in this article will 
be on cross-country comparisons. This is partly because most of the previous surveys on gender gaps in education have focused on the trends in the United States and the timing and the patterns differ across countries in interesting ways. ${ }^{1}$ Moreover, I strongly believe that focusing on cross-country data may shed new light on the factors underlying the observed gender differences in attainment. Finally, I will also survey available evidence on policies that have affected the gender balance in educational attainment.

The rest of the article is structured in the following way. In the next section, I document the trends in gender gaps in educational attainment. I will mostly focus on industrialized countries and put particular emphasis on the comparison of Nordic countries and the United States, which is the country that has traditionally led trends in educational attainment. In section 2, I examine the potential causes behind these trends. As a starting point I use the standard economic model of educational investments and look for gender differences in the trends of benefits and costs of education. The conclusion that arises from this analysis is that a combination of increasing returns to education, removal of barriers to women's careers and long-standing gender differences in the effort cost of education have made educational investment more attractive for women than for men. Section 3 explores the potential labor market implications. The recent trend of employment and wage polarization implies that increasing female and stalling male educational attainment will change the traditional patterns of gender gaps in labor market outcomes. In section 4, I survey evidence on the effects of different policies on the gender gap in educational attainment. I argue that the most relevant policies deal with achievement in secondary education or even earlier. Section 5 concludes.

\footnotetext{
${ }^{1}$ On American surveys see in particular Buchmann et al (2008) as well as Goldin et al (2006).
} 


\section{Changing gender differences in educational attainment}

When measuring educational attainment one can use both stock and flow measures. Stock measures reflect the pool of human capital available in the economy at a point in time whereas flows reflect the contributions of incoming cohorts to the stock of human capital. A number of researchers have constructed international datasets that attempt to measure both stocks and flows of human capital across a large number of countries. Perhaps the most famous of these dataset is the Barro and Lee data set (2010) which is based on census/survey information originally compiled by various international organizations such as Eurostat, OECD and UNESCO. ${ }^{2}$ Here I use the latest 2010 version of the Barro and Lee data to examine cross-country trends in gender gap in educational attainment.

In this section, I use cross-country data to examine gender differences in both stock and flows of human capital. In both of these measures, I start by looking at the mean outcomes. However, since the tails of the attainment distribution are in many ways more interesting, I put particular emphasis on gender differences in tertiary graduation and enrollment rates as well as on gender differences in the likelihood of not obtaining a secondary school diploma.

\subsection{Gender differences in stock measures of educational attainment}

Stock measures obviously take a longer time to reflect more recent changes in educational attainment. However, the process of female dominance in educational attainment has been going on for long enough so that it can be already seen in human capital stocks in many countries. Whereas in 1950, according to Barro-Lee data, women had more years of education

\footnotetext{
${ }^{2}$ According to Barro and Lee (2010) the latest version of their data addresses some of the measurement issues which were raised, among others, by de la Fuente (2012) in the previous issue of this review.
} 
than men in only 11 countries (Canada, UK, and USA among them) out of 146, in 2010 this figure was already 43 . These 43 countries include all the Nordic countries as well as Australia, United States, Canada, and the United Kingdom. Overall, in 9 out of 24 advanced economies in the Barro and Lee data the overall female population is on average more educated than the male population.

Also the pool of university graduates has become increasingly female in many countries. In 2010, there were more female university graduates than male university graduates in 13 out of 24 advanced economies in the Barro and Lee data set. In 1950, male university graduates still outnumbered women in all of these countries. The increase in the average educational attainment of women thus reflects the fact that increasing numbers of women are choosing to continue their education to the tertiary level.

1.2 Gender differences in flow measures of educational attainment

The trends in the stock of human capital mask interesting changes in the flow measures of human capital. Focusing on birth cohorts makes it clear that female educational attainment will surpass that of men in a majority of countries in the Barro and Lee data. Among individuals born between 1975 and 1979, women obtained more years of education than men already in 74 out of 144 countries. Hence, in many countries, where men still have higher average educational attainment than women, this situation will change in the near future. Among advanced economies, men born between 1975 and 1979 had higher educational attainment than women only in Austria, Germany, Switzerland, and Turkey. 

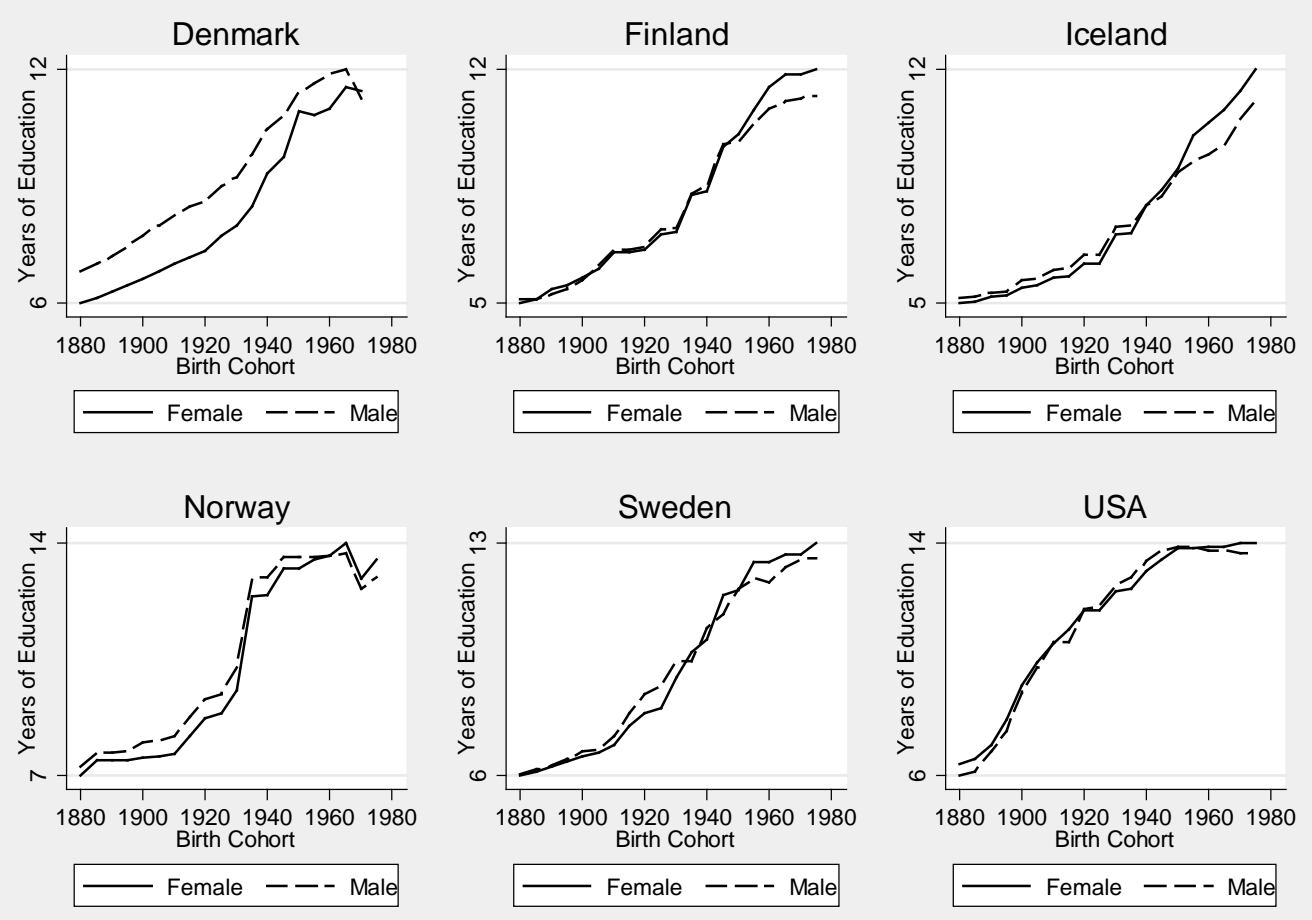

Figure 1: Female and Male average years of education by birth cohort and gender in the Nordic countries and in the United States. Source: Barro-Lee Data (2010)

In Figure 1, I have plotted the average years of education by gender and birth cohort in the Nordic countries and the United States. Barro and Lee data allows one to examine the educational attainment from cohorts born in the late $19^{\text {th }}$ century onwards. ${ }^{3}$ Figure 1 reveals that in the United States men had higher educational attainment in the cohorts born between 1920's and 1940's. However, in all of these countries, with the exception of Denmark, women caught up with men in educational attainment by the cohorts born in the 1950’s. After this the gender gap in average educational attainment has widened in favor of women. This widening of the gap reflects the fact that in most industrialized countries the growth in male educational attainment decelerated whereas female educational attainment kept on growing. This

\footnotetext{
${ }^{3}$ The Danish statistics for cohorts born after 1970 in the Barro and Lee data imply implausibly large drops in the level of educational attainment for both men and women. These data were not used in Figures 1 and 2 and this is why the Danish figures end with the cohort born in 1970.
} 
deceleration of the growth of male educational attainment is particularly dramatic in the United States where the growth has virtually stopped since the cohorts born in the 1940's.
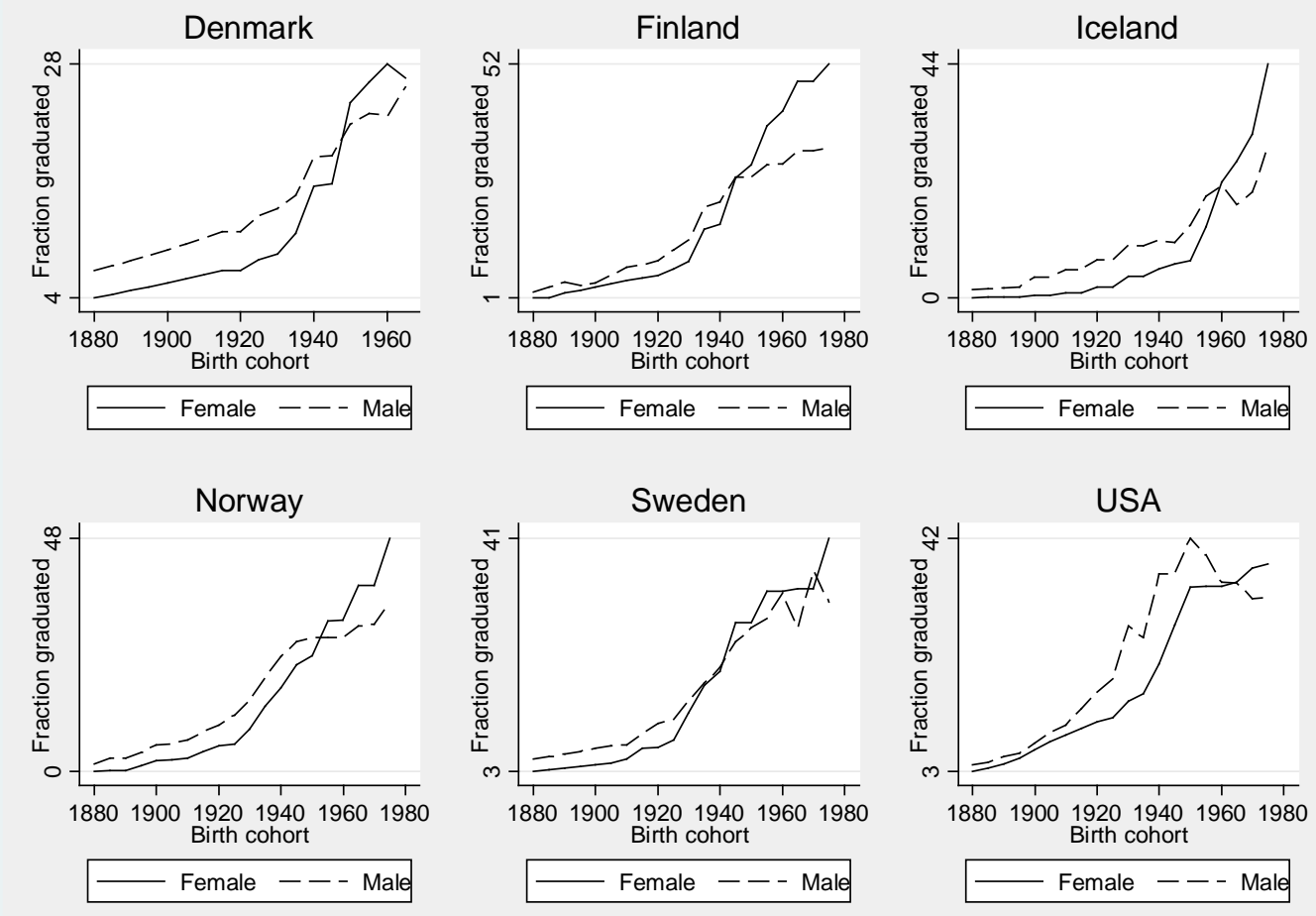

Figure 2: Female and Male university graduation rates by birth cohort and gender in the Nordic countries and in the United States. Source: Barro-Lee Data (2010)

Of course the average educational attainment simply gives us the mean of the distribution of human capital. The tails of the human capital distribution are often more relevant for labor market outcomes. Therefore it is interesting to focus on university education. These measures reveal even more dramatic gender differences. In the Barro and Lee data, women born between 1975 and 1979 completed university education at a higher rate than men in 21 out of 24 advanced economies. The three countries where this did not take place were Germany, Switzerland, and Turkey. In Figure 2, I have plotted the university education completion rates by birth year and gender in the Barro and Lee data. Gender differences are even clearer in Figure 2 than in Figure 1. In the United States, for example, the male university attainment 
started to drop after the cohorts born in the 1950's. At the same time, female university attainment continued to increase. Gaps in university attainment have become even larger in the Nordic countries. Yet in these countries attainment levels of both men and women have kept on increasing. The increasing gender gap in the Nordic countries reflects particularly fast growth of female university attainment.

Another way to look at the top end of the attainment distribution is to focus on enrollment in tertiary education. In the most recent data available from UNESCO for year 2008, out of 119 countries for which there are data on female enrollment in tertiary education was higher than the male enrollment in 81 countries. This is true for all the OECD countries with the exception of Japan, South Korea, Switzerland, and Turkey. But female enrollment in tertiary education is also higher in some large non OECD countries such as the Philippines, Iran, and Thailand. Indeed, according to UNESCO, globally the number of female students in tertiary education is almost 2.5 million higher than the number of male students, making the ratio of female to male students slightly higher than one at 1.03. It seems that female dominance in educational attainment is becoming a global phenomenon.

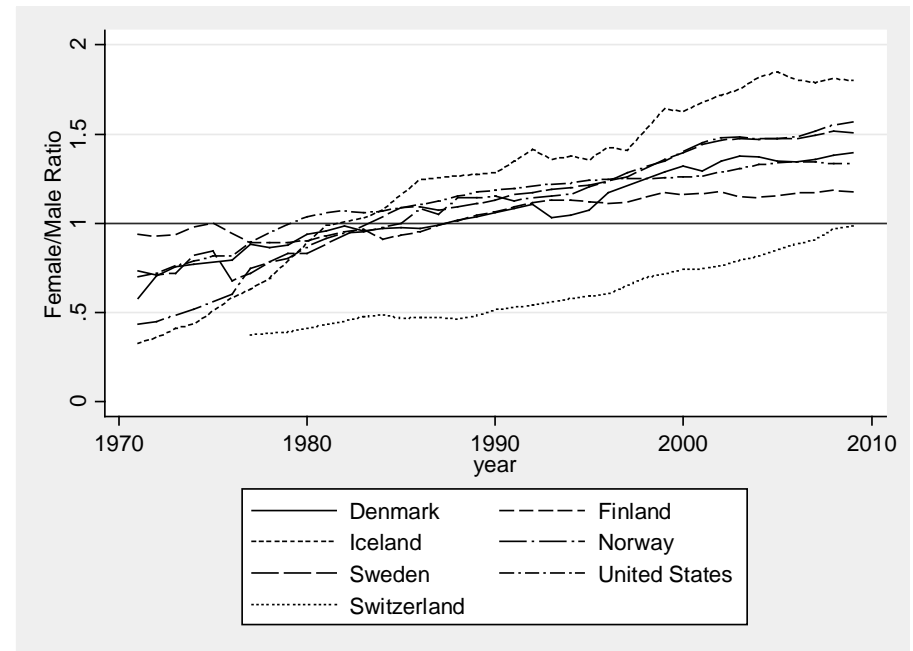

Figure 3: Ratio of female to male students at the tertiary level in the United States, Switzerland, and the Nordic Countries, 1970-2009. Source: The World Bank 
In Figure 3, I have plotted the ratios of female to male tertiary students in the United States, Switzerland and the Nordic Countries. The gender ratios in the U.S and the Nordic countries seem to increase almost in parallel fashion. The first country where the number of enrolled female students at the tertiary level surpasses the number of male students in this figure is United States where this happened in 1980. The Nordic countries followed the U.S approximately five years later and in all of these countries the ratio of female to male students has stayed above one and kept on increasing.

It is insightful to contrast the American and the Nordic enrollment ratios to those in Switzerland which, as was already explained above, is a country where female educational attainment has lagged behind other OECD countries. Swiss enrollment ratios are clearly below the U.S and Nordic ones. However, also in Switzerland the ratio of women to men among university students has kept steadily increasing in the past 40 years. In fact, all the OECD countries repeat the same pattern although they lag behind the U.S and Nordic countries somewhat. Judging from enrollment patterns female dominance in tertiary education will become stronger in the future in virtually all advanced economies.

\subsection{Gender differences in the choice of university major}

Despite the fact that women are now in majority among students at the tertiary level, women still choose different major subjects than men. Here, it is difficult to draw conclusions on international long-term trends since there are no long, internationally comparable time series available. However some studies on individual countries suggest that gender differences in choices of major subjects at the tertiary level may be diminishing. Both Turner and Boven 
(1999) and Goldin (2006) show that the dissimilarity index of college majors in the United States declined from close to 50 in 1970 to around 20 in $1994 .^{4}$ According to the World Bank data, the US dissimilarity index was still at 22 in 2009 which is the lowest figure in the OECD. The average level of the dissimilarity index in the OECD in 2009 is 29 with the highest level in Finland at 42. The data that are available from 1999 onwards do not reveal any striking trends in the gender differences in the choice of university major. However, in the majority of OECD countries dissimilarity index declined during this period with Denmark, Iceland, Japan, and Switzerland showing declines of more than 5 points.

1.3 Gender differences in secondary school drop-out rates

At the other end of the educational attainment distribution are individuals who do not finish upper secondary education. Although the compulsory education ends with lower secondary school in many industrialized countries, individuals without upper secondary school education are usually seen as a particularly disadvantaged group when it comes to labor market outcomes. Men have traditionally been overrepresented in this group.

\footnotetext{
${ }^{4}$ Dissimilarity index is calculated by summing the absolute values of the differences between the percentages of women and men in each field and dividing this sum by 2. A value of 100 for this index indicates total segregation by gender across fields and a value of 0 means that male and female choices are identically distributed.
} 


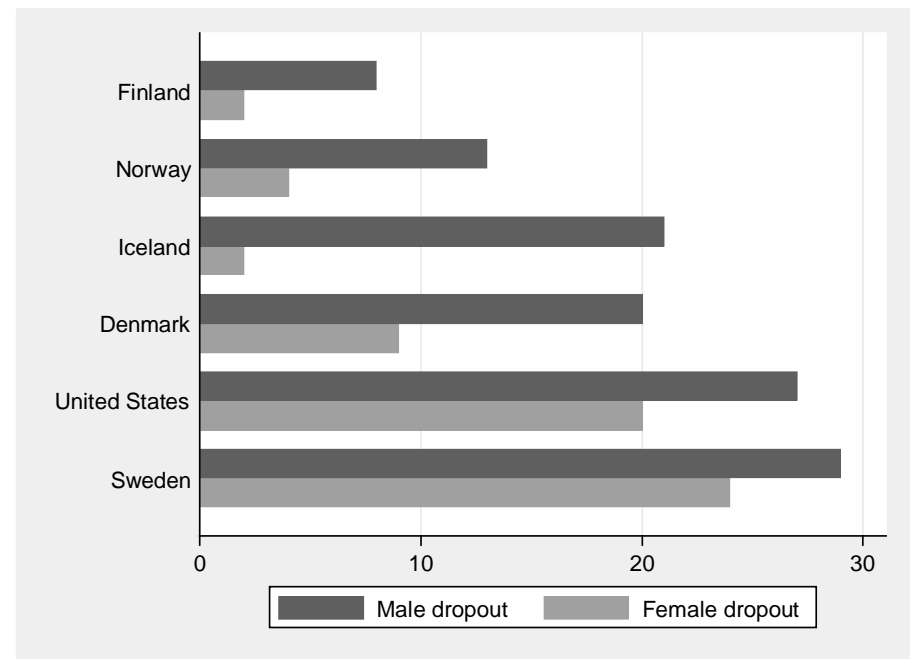

Figure 4: Fraction of male and female cohorts without upper secondary education in the Nordic countries and the United States in 2008. Source: OECD (2011).

In the OECD member countries in 2008, women are left without upper secondary education more often than men only in Germany and Switzerland (OECD (2011)). In Figure 4, I have plotted the fractions of both men and women who do not obtain upper secondary school diploma in the Nordic countries and in the United States. This figure reveals that there are large differences in the overall drop-out rates across countries with particularly high rates in Sweden and in the United States. However, what is really striking in Figure 4 is the gender difference. For example, in Iceland only $2 \%$ of girls are left without upper secondary education whereas the corresponding rate for boys is $21 \%$ making males more than ten times more likely leave school before obtaining upper secondary school diploma. The difference in Finland, where female and male drop-out rates are $2 \%$ and $8 \%$ respectively, is also very high. In fact, Finland and Iceland have the highest gender inequalities in the drop-out rates in the OECD. As I will argue below, the gender gap in secondary school drop-outs should be a cause of particular concern for policymakers. 


\section{Factors behind the emerging female dominance in educational attainment}

Standard economics textbook model of human capital investment views rational individuals as weighing the costs of additional education against the benefits from this investment. The costs of human capital investment include direct monetary costs such as tuition fees and the forgone labor market earnings during the time the individual is studying and indirect costs in the form of effort that the individual has to exert in order to acquire human capital through education. Even though education can yield some direct pleasure in the form of consumption value, the human capital theory assumes that the most important benefits to the individual from education are the direct labor market returns. Education should increase the productivity of individuals and therefore lead to higher earnings.

The traditional human capital model is a useful starting point for considering the potential causes underlying the dramatic shift in the gender gap in educational attainment. In particular, since male and female educational investments have performed differently over the past three or so decades, it seems logical to look for explanations for this divergence in gender differences in the marginal benefits and costs of education. In this section, I will discuss how gender differences in both benefits and costs of education have developed in industrialized countries in recent decades and whether they can be seen as a potential cause for the observed patterns in the gender gap in educational attainment.

\subsection{Gender differences in returns to education}

It is a welldocumented fact that the returns to education, and to university education in particular, have been increasing in most OECD countries since the early 1980's (Acemoglu 
and Autor (2011), Van Reenen (2011)). In the light of the large returns, one would expect to see strong supply responses in the form of increasing educational attainment. However, the evidence discussed in the previous section suggested that this is only true for female educational attainment whereas male educational attainment has only grown sluggishly or not at all. This has led many researchers to speculate that the returns to investment in education are higher for women than for men.

There are a huge number of studies that report returns to education estimates separately for men and women. A fairly consistent pattern in these studies has been that the average return to an additional year of education is somewhat higher for women than for men. Dougherty (2005) cites 27 U.S studies of which 18 report unambiguously higher returns for women. Trostel et al (2002) report estimates for 28 different, mostly European, countries of which in 24 returns are higher for women.

It is not clear, however, which level of schooling is responsible for different estimates of returns to schooling by gender. Whereas several earlier U.S studies seemed to imply that returns to university education were higher for women, these results have been recently called into question. Hubbard (2011) shows that previous studies fail to account for the top-coding of earnings in the available data and that once this is done there is no evidence on gender differences in returns to university education. Furthermore, it seems that the returns to university education have increased in the same way for both men and women since the early 1980’s. Whether the failure to account for top-coding in wage data also biases results from other countries is unclear, but it seems fair to conclude that the evidence on gender differences in returns to university education is mixed. 
However, it seems to be unambiguously true that the rates of returns comparisons mask large differences in favor of men in total earnings benefits of university education. Women still work less hours over the life cycle than men at all levels of education. Hence, even if there are no large differences in university premiums between men and women, men are still in a better position to reap the full financial benefits of university education than women.

Yet, in this respect changes over the past decades have been substantial. Female labor force participation has increased considerably in all OECD countries since the 1970's. The capacity of women to fully benefit from the financial rewards of educational investments has therefore improved in the recent decades. Moreover, as reported by Mulligan and Rubinstein (2008), the composition of female labor force has changed. Whereas the selection into female labor force was negative in the past in the sense that lower educated women had a higher probability of participating than high educated women, since the 1980's selection has become positive so that high educated women are more likely to participate in the labor force.

In the same way as higher labor force participation has increased the benefits of education for women also the changing role of family has improved the chances of women to reap the benefits from educational investments. Median age at first marriage has increased in virtually all industrialized countries. At the same time, divorce rates have increased making marriage more fragile. As a consequence the fraction of lifetime that individuals spend married has decreased substantially. This has meant that the value of economic independence has increased for women and the time during which they can benefit from educational investments in the form of labor market returns has become longer. 
Goldin (2006) as well as Goldin et al (2006) argue that these kinds of secular long-run changes in the labor market and in the role of the family in the United States increased the overall benefits of education for women and led young women to revise their expectations about their future role in the labor market somewhere in the 1970's. Citing survey evidence in the National Longitudinal Survey of Youth (NLSY), Goldin et al (2006) show that the fraction of young women who expected to be employed at age 35 increased substantially from the end of 1960's to the beginning of 1980's. They argue that the women who saw their mothers' generation participating in the labor market and postponing their marriage to an increasing extent decided to invest in education since they expected to be better able to benefit from investment in education. Indeed, Goldin et al (2006) show that those teenage girls in the NLSY that expected to be employed at the age of 35 were more likely to go to university.

While there are no international longitudinal data on the teenage expectations of women and their subsequent educational investments, one can use cross-country evidence to see whether the current female/male enrollment ratios at the tertiary level correlate with the labor market participation of the working age women and median age at first marriage in a way that is consistent with the argument that female educational investment increased at least partly as a response to an increase in the total benefits of education. 


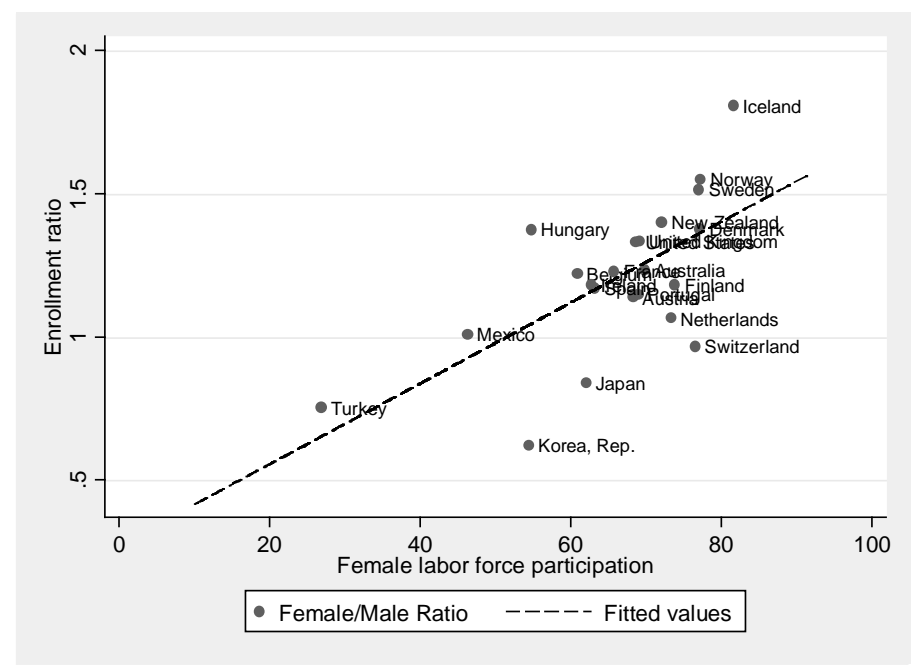

Figure 5: Female labor force participation rate and the female/male ratio of enrollment in tertiary education, OECD countries in 2007. Dashed line is the fitted regression of female/male ratio on female labor force participation (coefficient 0.014, $\mathrm{t}=3.76$ ) Source: UNESCO and World Bank.

Currently (in 2008) among the OECD countries, female participation rates range from $26 \%$ in Turkey to $81 \%$ in Iceland. The Turkish figure corresponds to the U.S. situation in the 1930's whereas the Icelandic figure is the highest that any industrialized country has reached in the recorded history. In Figure 5, I have plotted the female participation rates and female/male ratios in tertiary enrollment in the OECD countries in 2007 which is the last year for which there are data on enrollment. There is indeed a clear, positive correlation between female labor force participation and the ratio of women to men in tertiary enrollment. Furthermore, as both participation rates and enrollment ratios are available from 1980 for most countries, one can examine whether this positive relationship also holds within countries. For most OECD countries, there is a clear positive correlation between the female labor market participation and female/male ratio in tertiary enrollment. 


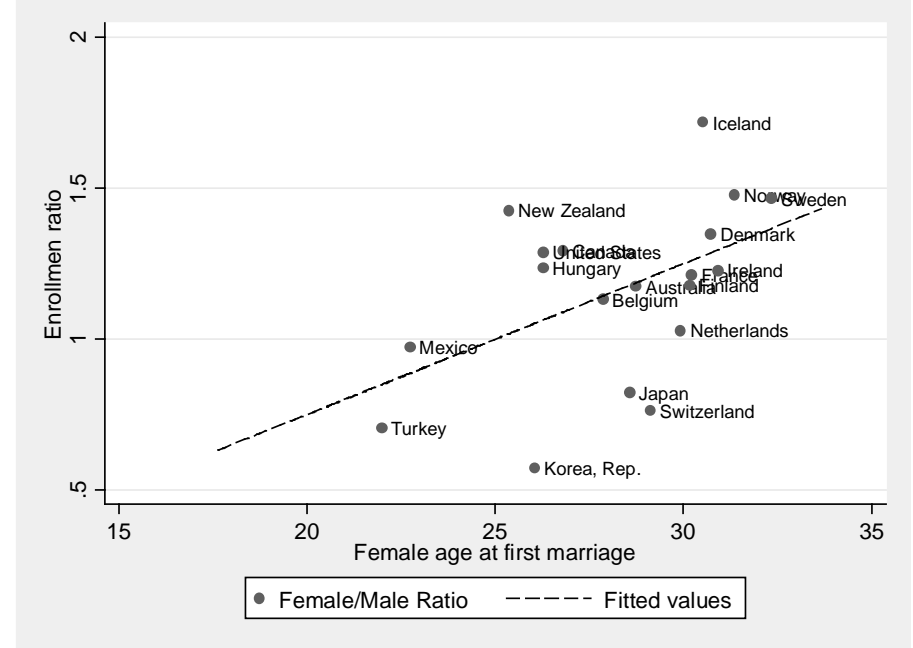

Figure 6: Median age at first marriage and the female/male ratio of enrollment in tertiary education, OECD countries in 2002. Dashed line is the fitted regression of female/male ratio on age at first marriage (coefficient 0.05, $\mathrm{t}=2.33$ ) Source: OECD Family Database.

A similar pattern is found between age at first marriage and enrollment rations across OECD countries. OECD's family indicators provide a snapshot of the situation in the OECD in 2002 and reveal that there is higher variation in the age at which individuals first marry across the OECD than within time in the United States. The median age at first marriage varies from 22 and 23 in Turkey and Mexico to 31 and 32 in Norway and Sweden, respectively. In figure 6, I have plotted the median ages at first marriage in the OECD against the tertiary enrollment ratios in 2002. The age at which individuals marry for the first time is clearly positively correlated with female/male enrollment ratios at the tertiary level.

Neither of the patterns in figures 5 or 6 indicates any causality. It seems likely that both the rise in female labor market participation and educational attainment may well be caused by some third factor. There is little agreement, let alone solid evidence, on what caused the changes in the labor market that enabled women to reap the benefits of educational investment. Some authors, such as Goldin et al (2006),claim that decreased discrimination 
removed barriers to women’s careers. Others, such as Chiappori et al (2009), build on the assumption that the technological change in the household production decreased the time spent on these activities. Perhaps the only piece of solid evidence on the underlying factors is the effect of contraceptive innovations. Goldin and Katz (2002) show that the diffusion of oral contraceptives across U.S states led to a postponement of marriage.

However, for the purposes of this survey the key lesson from the changes in the returns to education for men and women is that the total returns to education have increased more for women than for men. Yet the level of total returns is still likely lower for women. Hence, changes in the total returns are probably not enough to explain why women have overtaken men in educational attainment in most industrialized countries.

\subsection{Gender differences in the costs of education}

Since there apparently are no gender differences in the benefits of education that would be consistent with the observed gender gaps in attainment, it is logical to look for gender differences in the costs of education. As was explained above, the main monetary costs of education, especially at the tertiary level, consist of forgone labor market earnings as well as, in some countries, of tuition and other fees. Non-monetary costs of education, on the other hand, stem from the effort required to reach the desired attainment levels. Here, I go over the existing evidence on gender differences in these costs.

The literature quite clearly shows that there are no gender differences in the forgone earnings that would explain observed attainment differences. Indeed as will shown below, the recent changes in the labor markets in industrialized countries would actually imply that forgone 
earning have decreased for men since the wages and employment in medium skilled male jobs have decreased. Becker et al (2010) show that gender differences in the hourly earnings of college graduates relative to high school graduates are minor in the United States. Nor is there any evidence that direct monetary costs in the form of tuition or fees would be different for men and women.

However, there is a large literature showing that there may be considerable gender differences in the effort costs of education. The evidence on these differences is often indirect. For example, the pattern that girls achieve higher grades in secondary school is often cited to support this argument. ${ }^{5}$

More direct evidence for gender differences in the effort costs of education are related to differences in underlying cognitive and non-cognitive abilities. Differences in cognitive abilities have been a subject of long and contentious debate starting from the work by Maccoby and Jacklin (1974). A more recent survey on this literature by Spelke (2005) concludes that while there are some sex differences in intrinsic cognitive abilities, they are small and do not consistently favor either sex in a way that would make men or women cognitively more adept for schoolwork. ${ }^{6}$

Even if gender differences in tests measuring cognitive abilities are mixed, there are clear and consistent gender differences in the incidence of behavioral problems that imply differences in non-cognitive abilities. According to the medical and psychological literature surveyed by

\footnotetext{
${ }^{5}$ There is no international evidence on gender differences in grades. American studies show a consistent pattern that girls achieve higher grades from kindergarten to high school. Buchmann et al (2008) cite evidence starting from 1950's.

${ }^{6}$ This debate was contentious mainly because many commentators were interested in whether the gender differences in cognitive ability are biological or not. This debate is not resolved and is beyond the scope of this paper.
} 
Buchmann et al (2008) males are overrepresented in populations with reading disabilities, antisocial behavior, mental retardation, attention disorders, dyslexia, stuttering and delayed speech. There is also evidence that adolescent girls score higher in tests measuring noncognitive skills such as attentiveness, organizational skills, and self-discipline.

One would expect these differences in non-cognitive abilities to show up in educational attainment. Recent studies in economics (Heckman (2007)) suggest that non-cognitive abilities have direct and sizable effects on schooling. Indeed, Jacob (2002) shows that controlling for non-cognitive behavioral factors in a data set on U.S high school graduates from 1992 can explain the entire female advantage in the probability of continuing to college.

Standardized achievement tests on skills that are learned in schools are a useful composite measure of school performance and preparedness for further education. These tests do show consistent gender differences. Typically, male scores are, on average, somewhat higher in tests measuring mathematical skills and women score clearly higher in tests measuring verbal skills. However, irrespective of the subject, the variance of tests scores seems to be higher for men (Hedges and Nowell (1995), Machin and Pekkarinen (2008)). 


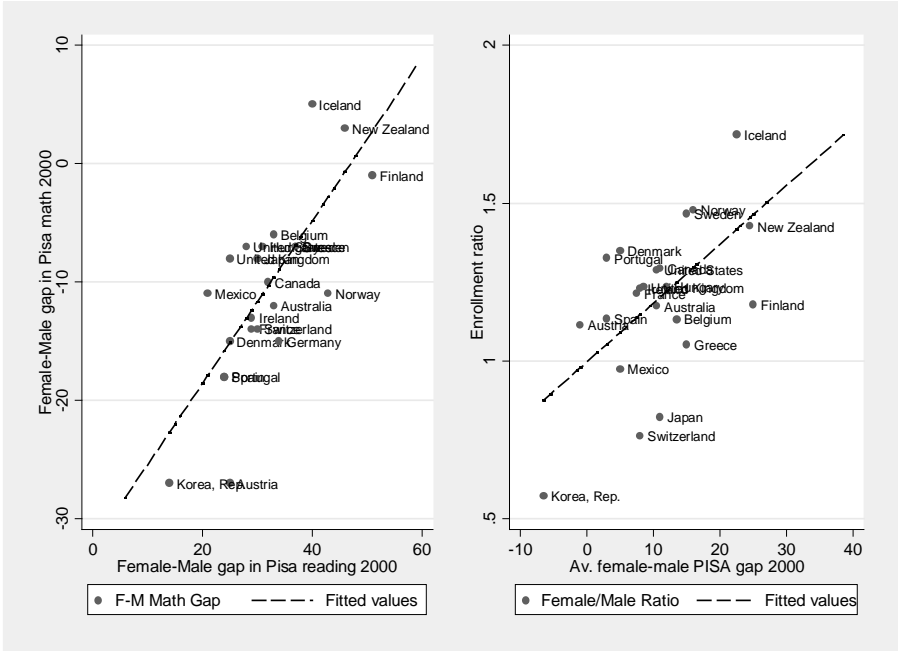

Figure 7: (Left) The relationship between female-male gaps in reading and mathematics in 2000 PISA test scores, (Right) The relationship between the average female-male gap in PISA 2000 test scores and the female/male enrollment ratio in tertiary education. Source: OECD and UNESCO.

Interestingly there is considerable variation in the size of gender gaps in achievement tests across countries. Here, I use OECD’s PISA tests to examine cross-country differences in gender gaps more closely. PISA measures skills learned in lower secondary school across OECD countries in a comparable way. In the left-hand side figure of Figure 7, I show that the gender gaps in mathematics and reading are highly correlated across countries in PISA 2000. When female-male gender gaps in reading are high, the gaps in mathematics tend to be close to zero or even positive as in Iceland and New Zealand. This pattern suggests that there are cross-country differences in the relative performance of women irrespective of the subject matter being tested.

In the right-hand side figure of Figure 7, I have plotted the average female-male gender gap against the female/male ratio in university enrollment. The pattern in this figure is very clear. 
The higher the gap in favor of women, the higher is the female/male enrollment ratio in universities. This positive correlation suggests that in countries where women perform relatively better in secondary school achievement, women also participate in higher education in higher numbers. Since the skills that are learned in secondary schools should be directly related to the effort costs of education at the tertiary level, one can interpret the evidence in Figure 7 as support for the claim that the gender differences in the effort costs of education are related to gender gaps in educational investment in a consistent way.

\subsection{Gender differences in the net returns}

The combination of increasing returns to education for both men and women and the lower effort cost of education for women imply that the net returns to education have become higher for women than for men. Whereas the effort costs of education probably have been lower for women already before the female educational attainment surpassed male attainment, the fact that the total benefits of education have increased more for women through increasing labor force participation and delayed marriage means that female educational investment started to reflect lower effort costs only after these barriers for women’s career were diminished.

Becker et al (2010) argue that this combination of demand-driven increases in returns and long-standing female advantage in costs explains the emerging female dominance in educational attainment. They also argue that the evidence on the gender differences in the distributions of both cognitive and non-cognitive test scores imply that the supply of female human capital is more elastic than the male supply at the higher education levels. The lower female variance in school achievement implies that as the returns to university education 
increase there will more women at the threshold where investment in university education becomes profitable.

\section{Labor market consequences of the female dominance in educational attainment}

When considering the labor market consequences of the changes in the gender balance of educational attainment discussed above, it is important to remember that according to patterns in Figures 1 and 2 gender gaps in educational attainment are increasing because the growth of male attainment has either stalled or started to decline and because female attainment has kept on increasing. This pattern implies a dramatic change in the composition of skill supply in the industrialized economies. Moreover, this change happens at a time when demand-driven changes in the labor market have made the skills acquired through education exceptionally important.

Although increasing returns to education and the growth in overall earnings inequality in industrialized countries over the past three decades is a well-documented trend, the recent literature in labor economics has highlighted some important patterns in the labor market that further underline the importance of skills for labor market outcomes. In a recent survey of the literature, Acemoglu and Autor (2011) show that in addition to the increasing returns to college education, the level real earnings of low skilled workers has actually declined since the early 1980's in the United States. At the same time both wage growth and employment have become "polarized" so that wages at the lower and upper tail of the wage distribution have grown more relative to the middle and the employment shares of low-skill and highskill occupations have grown whereas the employment share of occupations in the middle of 
the skill distribution have decreased. Many of these trends, although not identical, are also visible in the European Union as shown by Goos et al (2009).

What these changes imply is that the wages and employment in traditional middle skill jobs are declining both in the United States and the European Union. These jobs include titles such as sales and office workers, production workers, and operatives. According Acemoglu and Autor (2011) the employment share of these job titles decreased from 57 to 46 percent between 1979 and 2009 in the United States. At the same time, the employment in low-skill service occupations and high-skill managerial jobs increased considerably.

The most likely explanation for these changes is demand-driven. Rapid technological change, and computerization in particular, has made it possible to substitute technology for labor and this has been most feasible in tasks for which modern computers are suitable. They are typically routine tasks that were traditionally performed by workers in middle-skill occupations. At the same time, technological change has increased the demand for workers who perform tasks that computers cannot do. These involve abstract tasks performed by workers in high-skill tasks as well as manual tasks performed by workers in low-skills tasks.

Naturally these changes, albeit important at the aggregate level, need not imply anything for gender differences. And indeed it is true that, at least in the United States, the employment in middle-skill occupation has decreased for both men and women. However, Acemoglu and Autor (2011) show that the disappearance of middle-skill jobs has had different consequences for male and female employment. Whereas female employment has shifted predominantly to high-skill and highly paid jobs, male employment has shifted to both tails of the occupational distribution. Women have moved upward in the occupation distribution with barely any 
growth in low-skill employment. On the other hand, the shift for men has been more evenly split with actually a slightly higher increase in low rather than in high-skill employment.

Changes in earnings mirror changes in the employment shares in the United States. For male secondary school graduates real earnings declined by more than 10 percent between 1979 and 2009 whereas the real earnings of university graduates increased by approximately same share. Again, the change in female distribution is more positive. There was actually a small increase of 6 percent for female secondary school graduates whereas the real earnings of female university graduates increased by almost 30 percent. Overall, these changes imply a significant worsening of earnings and employment prospects for male workers with mediocre skills.

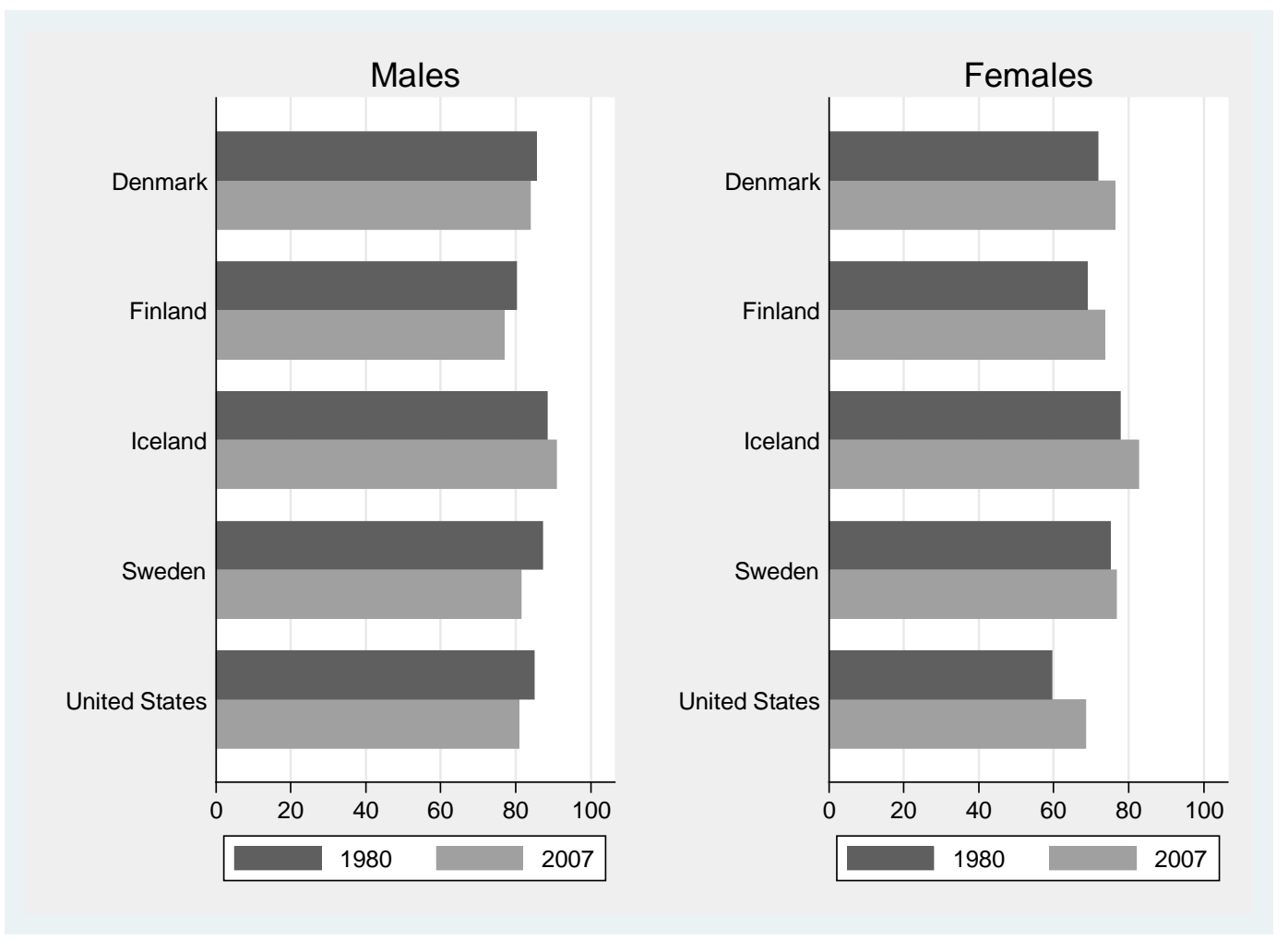

Figure 8: Male and female labor force participation rates in 1980 and 2007 in the United States and in the Nordic countries. Source: World Bank Data Bank. 
Although the aggregate changes in the employment shares are likely caused by demand side factors, it seems likely that the differential consequences of these changes by gender are linked to gender differences in educational attainment. Indeed, long run trends in male and female participation rates seem to support this connection, as is shown in Figure 8. Between 1980 and 2007, the male labor force participation declined in all the OECD countries except in Iceland. At the same time, female participation rates increased in all of these countries. Furthermore, Autor (2010) shows that in the United States the decline in the labor force participation was strongest for men with only secondary school education whose participation rate declined by more than 10 percentage points. It seems likely that these changes in participation rates reflect responses to declining earnings and employment opportunities. The fact that the male educational attainment is lagging behind female educational attainment at a time when the prospects for low educated workers are particularly bleak, is causing low educated men to drop out of the labor force.

\section{Policy implications}

It is not of course entirely obvious that the gender gap in educational attainment should be a policy concern. First of all, gender gap may simply reflect different rates of growth of educational attainment. Yet, the evidence cited above suggests that in many countries the widening gender gap in educational attainment reflects stalling or even declining male educational attainment. In particular, the fraction of male cohorts continuing to postsecondary education has stalled or started to decline in a number of countries. This is a cause for concern since there is a large body of evidence showing that returns to university education are large and increasing (Acemoglu and Autor (2011), Van Reenen (2011)). 
According to this evidence a significant fraction of male cohorts are missing out of education that would benefit them.

Second reason for why policies shouldn't perhaps primarily focus on the gender gap is that male gender may simply be a proxy for poor performing students. Any policies that would help students at the lower end of the achievement distribution would necessarily decrease the gender gap in achievement since boys are overrepresented among the low achievers. While this is partly true, there are reasons to focus specifically on poor performing males. In particular, there is some basis for the argument that the negative externalities from low male educational attainment are large. Lochner and Moretti (2004) show that education has a negative causal effect on male criminality and calculate that a $1 \%$ increase in male high school graduation rates in the U.S would save as much as $\$ 1.4$ billion. Since women are much less likely to commit crimes, low female educational attainment does not generate these kinds of negative externalities. Furthermore, Autor (2011) argues that declining male educational attainment is at least partly responsible for the fragile state of lower-income families in the U.S.

As the evidence presented above showed, the gender gap in performance opens up earlier that at university entry. Hence it is not surprising that the existing studies show that women respond more strongly to lowering the costs of university education (Dynarksi (2008)) or that women respond more to incentives to perform well in university (Angrist et al (2009)). This is why I will focus on policies that affect performance at the earlier stages of education. There are very few studies evaluating the effects of policies that specifically target the gender gap in achievement. Notable exceptions are studies that focus on the effects of the gender of the teacher and the peer groups on student achievement. Otherwise, there are numerous studies on 
the effects policies that attempt to improve the outcomes of poorly performing students. These policies can be classified as policies that change school resources or anticipate educational interventions. Jacob and Ludwig (2008) provide an elegant survey of the overall effects of these kinds of policies. Finally, the structure of the educational system, and in particular the timing of school tracking into academic and vocational tracks, has been shown to affect gender differences in educational attainment. Here, we focus on the effects of each of these policies on poorly performing males and on the gender gap in achievement.

\subsection{Gender of the teachers, peer groups, and teaching practices}

The fact that females are hugely overrepresented in teacher profession in most industrialized countries has led many commentators to speculate that one of the sexes (which one it is depends on the commentator) is discriminated against in assessment of students. The best available evidence on this issue is mixed. There are some studies that hint at potential bias against boys. In particular, Lavy (2008) finds that in Israeli high schools boys score higher grades in blind-tests where the gender of the student is not revealed than in non-blind tests where the grader observes the gender. This result would suggest that boys are discriminated against. However, it is not clear whether the blind and non-blind tests actually test the same thing. In a recent Swedish study where exactly the same tests are graded blindly and nonblindly, Tyrefors et al. (2011) find no evidence of discrimination against either sex

There are also signs that single-sex education is attracting more support in some countries. For example, Buchmann et al (2008) report that in the United States there were 233 public schools offering gender-separate education in 2006 whereas in 1998 there were just 4 . The effect of single-sex education on student achievement is a difficult topic because selection to 
these schools if far from random. However, the best available studies on the effect of the gender composition of the peer groups (Lavy and Schlosser (2011) and Hoxby (2000)) suggest that single-sex schooling would exacerbate gender differences in attainment rather than reduce them. The achievement of both boys and girls is increasing in the fraction of females in their peer groups.

Changes in teaching practices have also been suggested as a potential strategy of reducing gender gaps in achievement. It is often argued that boys are more sensitive to poor teaching. This concern led to a policy experiment in the UK, where primary schools were given highly structured instructions on teaching objectives and class management for daily "literacy and numeracy hours”. Machin and McNally (2008) is an evaluation of this experiment and they show that this strategy was successful in improving the test scores of both boys and girls. However, the effects were always larger in magnitude for the sex that is generally weaker in the particular subject. Hence, these literacy and numeracy hours were successful in reducing gender gaps in achievement.

\subsection{School resources}

Whereas the characteristics of the teachers and teaching practices are often affected by policies only indirectly, the school resources are a fairly simple instrument for the politicians to manipulate. Especially reducing class size through increasing the number of teachers is a very attractive policy tool. The effectiveness of these policies, however, has been a subject of rather heated debate in the research literature for a long time. The raw correlation between class size and student achievement is usually very weak and major reductions in class size over time have not led to major increases in test scores. Still, careful studies of randomized 
and natural experiments on class size reductions do show that reducing class size may improve student achievement and is often effective in reducing gender gaps as well.

The most carefully studied experiment in class size reductions is the STAR experiment which randomly assigned students and teachers to classes of different sizes within schools in Tennessee. The short-term effects of this experiment on test scores were studies by Krueger (1999) whereas Chetty et al (2011) provide an analysis of long-term outcomes such as completed schooling and earnings. Interestingly these studies show that reducing class size by one third improved both the short-term (test scores) and long-term (completed schooling) outcomes more for men than for women. It is not clear, however, whether the class size reduction was effective in targeting the long-term outcomes of men at the lower end of the achievement distribution. Whereas the results in Krueger (1999) suggest that the experiment also improved the test scores of students from poor families (students receiving free school meals), Chetty et al (2011) report that the long-term effects were stronger for high income students.

Fredriksson et al (2011) show similar results from a natural experiment in Sweden where administrative rules create exogenous changes in class sizes. Using this variation, the authors find that class size reductions, also in this case, have stronger effects on men but at the same time they increase the achievement gaps between students from rich and poor families. Hence, even though it seems that reducing class size may be an effective tool of reducing gender gaps in achievement, we cannot be sure whether they are successful in targeting the achievement of poorly performing males which should be the main target group, if we are concerned about the gender gap. 


\subsection{Early intervention}

Early intervention programs have become very popular especially in countries, such as United States, where publicly provided pre-school is not widely available. The popularity of the early intervention programs is due to their impressive short-term and long-term outcomes on average. Indeed, the importance of early education is one topic on which most of the researchers in economics of education agree.

However, there has been some controversy regarding the effects of these policies on gender gaps in achievement. Whereas the early studies seemed to suggest that early interventions were more effective for boys, more recent studies that pay more attention to the identification of the effects find that the early intervention programs actually tend to widen the gender gap in schooling outcomes. Ludwig and Miller (2007) focus on the Head Start which is the largest of the American early intervention programs and provides preschool, health and other social services to over 900,000 children. According to their results, there is no consistent support for the claim that Head Start would reduce gender gaps in long-term scholastic achievement. Similarly, Anderson (2008) who looks at much smaller scale Abecedarian, Perry Preschool, and Early Training projects finds that, if anything, these programs increased the gender gap in achievement by significantly improving later-life academic outcomes of women while failing to have any effect on male outcomes. ${ }^{7}$

The Nordic countries of course have a much longer experience with universal, publicly provided preschool than the U.S. It is therefore not clear how the results of the American studies generalize to Nordic countries. Havnes and Mogstad (2011) analyze the long-term

\footnotetext{
${ }^{7}$ Heckman et al (2010) is a reanalysis of the Perry Preschool programs which confirms the findings in Anderson (2008) when it comes to academic outcomes. However, Heckman et al (2010) do find that the program had significant crime reducing effects on men.
} 
effects of the publicly provided preschool in Norway. When it comes to educational outcomes, the Norwegian preschool benefitted both men and women. However, the effects were slightly larger for men and clearly concentrated on children from low-educated families. Hence, this study strongly suggests that the Nordic style, national scale preschool programs can be effective in targeting the poorly performing males and in increasing their long-term educational attainment.

\subsection{Tracking}

As can be seen from the papers cited in this chapter, most of the policy discussion in this literature is from the United States and naturally deals with the type of institutions that are of interest to American policymakers. Therefore many institutional features that are typical in the European context and may affect gender gaps in achievement are not dealt with in this literature. One important institutional dimension in which European educational systems differ from each other is the timing of tracking in the secondary school to academic and vocational tracks. In some countries, such as Germany and Austria, this is done early at ages 10 to 11 whereas in other countries, such as the Nordic countries, the tracking takes place when students are 15 to 16 years old.

Some authors have speculated that the timing of tracking may explain why gender gaps in attainment are low in the early tracking countries and high in late tracking countries. As we have already seen, Germany and Austria have female/male enrollment ratios of around one in tertiary education. Perhaps even more interestingly though, according to the OECD (2011), there are large differences across countries in the female/male enrollment ratios in the academic track at secondary school. In Germany and Austria these ratios are actually below 
one whereas in the Nordic countries they vary from 1.06 in Denmark, Norway, and Sweden to 1.12 in Iceland. One explanation for these differences is that gender differences in maturity are larger at ages 15 to 16 when many boys are still going through adolescence than at ages 10 to 11. Pekkarinen (2008) studies the effect of the Finnish comprehensive school reform on gender gap in educational attainment and finds that moving from early to late tracking system exacerbated the gender gap in the likelihood of choosing the academic track in upper secondary school.

\section{Conclusion}

The rapid growth in female educational attainment is one of the most striking trends in education statistics in the post WWII world. In an increasing number of industrialized countries female educational attainment is now higher than male educational attainment. Women are in majority among secondary school graduates, among tertiary level students, and among tertiary level graduates. Judging from recent trends in international data, it seems likely to that female dominance in educational attainment is becoming stronger in the coming decades.

Evidence on the returns and costs of education suggests that the emerging female dominance in education is caused by a combination of increasing returns to both men and women and lower female effort costs of education which has meant that the net returns to education, particularly at the higher levels, have increased more for women than for men. Whereas the level of total benefits of education are probably still higher for men, they have increased more for women over the past three decades through removal of barriers to women's careers. The 
effort costs of education, on the other hand, have been lower for women for a long time due to gender differences in non-cognitive abilities.

The fact that the widening gender gap in education partly reflects stalling or even falling male educational attainment is a cause for concern for policymakers since recent trends in the labor market make education ever more important for labor market outcomes. There is plenty of evidence showing that the medium-skill well-paid jobs are rapidly disappearing and that loweducated men are increasingly employed in low-paid low-skill jobs. Furthermore, there are signs that male participation rates are declining across the whole OECD and that this decline is particularly strong for low-educated men.

Although there is scarce evidence on the effects of policies that would directly target gender inequalities in education, one can draw some conclusions on the effectiveness of different policies indirectly. First of all, it seems to be the case that single-sex education is more likely to widen gender gaps in education than to decrease them. However, there are indications that male students are more responsive to school resource investments such as reductions in class size. Early intervention policies, on the other hand, seem to be more effective in improving both female and male long-term outcomes without reducing gender gaps. There is also suggestive evidence that the structure of educational system, and the timing of tracking in secondary school in particular, affects male and female students differently. 


\section{Literature}

Acemoglu, D. and Autor, D. (2011), Skills, tasks, and technologies: Implications for employment and earnings, in Ashenfelter, O. and Card, D. (eds.), Handbook of Labor Economics, Volume 4b, Elsevier B.V., Amsterdam.

Anderson, M. L., (2008), Multiple inference and gender differences in the effects of early intervention: A reevaluation of the Abecedarian, Perry Preschool, and Early Training Projects, Journal of the American Statistical Association, 103 (484), 1481-1495.

Angrist, J. D., Lang, D., and Oreopoulos, P., (2009), Incentives and services for college achievement: Evidence from a randomized trial, American Economic Journal: Applied Economics, 1 (1), 136-163.

Autor, D., (2010), U.S. labor market challenges over the longer term, mimeo, Massachusetts Institute of Technology.

Barro, R. J. and J-W Lee, (2010), A new data set of educational attainment in the world, 1950-2010, NBER Working Paper 15902.

Becker, G. S., Hubbard, W. H. J., and Murphy, K. M., (2010), Explaining the worldwide boom in higher education of women, Journal of Human Capital, 4 (3), 203-241.

Buchmann, C., DiPrete, T. A., and McDaniel, A. (2008), Gender inequalities in education, Annual Review of Sociology, 34: 319-37.

Chiappori, P-A., Iyigun, M., and Weiss, Y., (2009), Investment in schooling and the marriage market, American Economic Review, 99 (5), 1689-1713.

Chetty, R., Friedman, J. N., Hilger, N., Saez, E., Schanzenbach, D. W., and Yagan, D., (2011), How does your kindergarten classroom affect your earnings? Evidence from project STAR, Quarterly Journal of Economics, forthcoming. 
de la Fuente, A. (2012), Human capital and productivity, Nordic Economic Policy Review, forthcoming.

Dougherty, C. (2005), Why are returns to schooling higher for women than for men? Journal of Human Resources, 40 (4): 969-88.

Dynarski, S., (2008), Building the stock of college-educated labor, Journal of Human Resources, 43 (3), 576-610.

Fredriksson, P., Öckert, B., and Oosterbeek, H., (2011), Long-term effects of class size, IZA Discussion Paper 5879.

Goldin, C. (2006), The quiet revolution that transformed women's employment, education, and family, American Economic Review Papers and Proceedins, 96 (2): 1-21.

Goldin, C. and Katz, L. F., (2002), The power of the pill: Oral contraceptives and women’s career and marriage decisions, Journal of Political Economy, 110 (4), 730-70.

Goldin, C., Katz, L. F., and Kuziemko, I. (2006), The homecoming of American college women: The reversal of the college gender gap, Journal of Economic Perspectives, 20 (4): 133-56.

Goos, M., Manning, A., and Salomons, A., (2009), The polarization of the European labor market, American Economic Review Papers and Proceedings, 99 (2).

Havnes, T., and Mogstad, M., (2011), No child left behind: Subsidized child care and children’s long-run outcomes, American Economic Journal: Economic Policy, 3, 97-129. Heckman, J. J., (2007), The economics, technology, and neuroscience of human capability formation, PNAS, 104 (33), 13250-13255.

Heckman, J., Hyeok Moon, S., Pinto, R., Savelyev, P., and Yavitz, A., (2010), A reanalysis of the High/Scopre Perry Preschool Program, mimeo, University of Chicago.

Hedges, L. V. and Nowell, A., (1995), Sex differences in mental test scores, variability, and numbers of high-scoring individuals, Science, 269 (5220), 41-45. 
Hoxby, C., (2000), Peer effects in the classroom: Learning from gender and race variation, NBER Working Paper, 7867.

Hubbard, W. H. J., (2011), The phantom gender gap in the college wage premium, The Journal of Human Resources, 46 (3), 568-85.

Jacob, B. A., (2002), Where the boys aren't: Non-cognitive skills, returns to school and the gender gap in higher education, Economics of Education Review, 21, 589-598.

Jacob, B. and Ludwig, J., (2008), Improving educational outcomes for children, NBER Working Paper, 14550.

Krueger, A., (1999), Experimental estimates of education production functions, Quarterly Journal of Eonomics, 114 (2), 497-532.

Lavy, V., (2008), Do gender stereotypes reduce girls' or boys' human capital outcomes?

Evidence from a natural experiment, Journal of Public Economics, 98, 2083-2105.

Lavy, V. and Schlosser, A., (2011), Mechanism and impacts of gender peer effects at school, American Economic Journal: Applied Economics, 3, 1-33.

Lochner, L. and Moretti, E., (2004), The effect of education on crime: Evidence from prison inmates, arrests, and self-reports, American Economic Review, 94 (1), 155-189.

Ludwig, J. and Miller, D. D., (2007), Does Head Start improve children’s life chances?

Evidence from a regression discontinuity design, Quarterly Journal of Economics, 122 (1), 159-208.

Maccoby, E. E. and Jacklin, C. N., (1974), The Psychology of Sex Differences, Stanford University Press, Palo Alto, CA.

Machin, S., and MacNally, S., (2008), The literacy hour, Journal of Public Economics, 92 1441-62.

Machin, S., and Pekkarinen, T., (2008), Global sex differences in test score variability, Science, 322, 1331-1332. 
Mulligan, C. B. and Rubinstein, Y. (2008), Selection, investment, and women’s relative wages over time, Quarterly Journal of Economics, 122 (3): 1061-1110.

OECD (2011), Education at a Glance 2011.

Pekkarinen, T., (2008), Gender differences in educational attainment: Evidence on the role of tracking from a Finnish quasi-experiment, Scandinavian Journal of Economics, 110 (4), 807825.

Spelke, E. S., (2005), Sex differences in intrinsic aptitude for mathematics and science? A critical review, American Psychologist, 60 (9), 950-958.

Trostel, P., Walker, I., and Woolley, P., (2002), Estimates of the economic return to schooling for 28 countries, Labour Economics, 9 (1), 1-16.

Turner, S. E. and Bowen, W. G., (1999), Choice of major: The changing (unchanging) gender gap, Industrial and Labor Relations Review, 52 (2), 289-313.

Tyrefors Hinnerich, B., Höglin, E., and Johanneson, M., (2011), Are boys discriminated in Swedish high schools?, Economics of Education Review, forthoming.

Van Reenen, J., (2011), Wage inequality, technology and trade: $21^{\text {st }}$ century evidence, Labour Economics, forthcoming. 